\title{
Literatura e Experiência Histórica em Sartre: o engajamento
}

\author{
Franklin Leopoldo e Silva \\ Universidade de São Paulo
}

resumo 0 texto procura comentar as condições éticas e políticas do compromisso histórico, destacando o caso do engajamento do escritor. Pa ra isso relacionamos as noções de intersubjetividade e transitividade da prosa, no intuito de esclarecer o que Sartre denomina "encont ro de liberdades", compromisso recíproco assumido ent re escritor e leitor no que se refere à produção de significações. Esse compromisso, compreendido a partir do exercício da liberdade situada, manifesta, no contexto da relação escritor/leitor, o caráter decisivamente revelador da alteridade como estrutura existencial e experiência histórica.

palavras-chave compromisso histórico; liberdade; intersubjetividade; alteridade.

\begin{abstract}
"Um livro possui sua verdade absoluta na época. É vivido como revolta, como penúria. Com muito menos intensidade, por certo, e por muito menos gente: mas da mesma maneira. É uma emanação da intersubjetividade, uma relação viva de raiva, de ódio, ou de amor entre aqueles que o produziram e aqueles que o recebem. Em meio a uma época, cada palavra, antes de ser histórica ou origem de um processo social, é de início um insulto, um apelo ou uma confissão (...) as idéias são instrumentos ou fugas, os atos nascem da intersubjetividade e a perturbam, como as emoções de uma alma individual."
\end{abstract}

(SARTRE, 1970, p. 672).

Começamos citando esse texto por três razões, que são as três relações nele estabelecidas. Em primeiro lugar, a ligação entre o compromisso e o Recebido em 03 de maio de 2006. Aceito em 30 de junho de 2006. doispontos, Curitiba, São Carlos, vol. 3, n. 2, p.69-81, outubro, 2006. 
livro, talvez a definição mais simples e direta do engajamento intelectual. Em segundo lugar, o vínculo entre intersubjetividade e história, a nos mostrar que a gênese da palavra histórica está na fala intersubjetiva. Em terceiro lugar, a relação entre idéias, atos e subjetividade singular indicada pela analogia entre as emoções e a alma individual.

Numa leitura mais atenta, contudo, as três relações podem ser remetidas àquela que é mencionada em último lugar, como se as duas outras nascessem dela. Com efeito, a verdade absoluta que um liv ro possui na sua época não deriva de uma fundamentação objetiva ou de uma descrição analítica que nos proporcionasse alguma explicação total do tempo histórico, elaborada por via de mediações científicas. A verdade do livro é vivida primeiramente como a ve rdade da revolta e da miséria, numa dimensão absoluta que se dá dentro da experiência subjetiva. Essa vivência, menos intensa do que a das carências subjetivas é, entretanto, semelhante devido ao caráter direto da participação do sujeito no absoluto vivido da verdade, no contexto de uma intersubjetividade em que os sentimentos são partilhados: o ódio, a raiva, o amor que constroem a comunicação entre os interlocutores, isto é, os produtores e os receptores. E assim a palavra traz primeiramente a carga subjetiva da produção de um significado absolutamente direto, na medida em que serve para insultar, para apelar, para confessar ainda em termos de relação imediata entre os sujeitos, muito mais emotiva do que socialmente estruturada. Tudo se passa como se houvesse alguma pretensão de comunicação intersubjetiva direta, algo que, no entanto, sofreria sempre a perturbação derivada dos próprios cortes constituintes de uma intersubjetividade problemática. Então, a palavra que se quer instrumento de algum modo tem a sua utilidade frustrada pela opacidade relativa que torna impossível uma comunicação intersubjetiva governada pela instrumentalidade, isto é, pela univocidade pragmática do significado. A palavra parece participar da incompletude expressiva das emoções.

Na própria dimensão originária de uma fala mais direta as palavras já encontram os obstáculos que se interpõem na passagem do dizer ao ouvir - ou mais precisamente entre a produção da escrita e a recepção pela leitura, pois é dessa relação que na verdade se trata. Mas não se cogita aqui de qualquer alusão a um possível drama da incomunicabilidade. Trata-se, antes, da estrutura da relação entre a produção do texto e a sua apreensão, 
uma relação que na prosa é sempre transitiva, entendendo-se por isso a dupla atividade de constituição das significações, sempre dependente tanto do escritor quanto do leitor. Ora, se no princípio dessa relação estão os vínculos vivenciais que se podem manifestar pelo insulto, pelo apelo, pelo amor e pelo ódio, o estrato intersubjetivo da comunicação nunca aparecerá como uma instância transpessoal ou objetiva, constituída pelas subjetividades singulares que se relacionam. Dito de outro modo, quando as palavras se traduzirem em processos sociais, elas jamais serão apenas operadores desses processos, p o rque a dimensão subjetiva produtora de significações não se perderá; ela se transformará ao encontro da dimensão objetiva pela qual se apreendem as significações, o que só pode ser feito por uma nova produção e por outros sujeitos participantes da relação.

A palavra se torna histórica da mesma forma que a ação: através de uma produção subjetiva da qual emana algo que se desprende do sujeito, que dele se distancia a ponto de até mesmo tornar-se estranha ao próprio sujeito que produziu. Assim como no caso da ação, temos de considerar duas faces que se manifestam muitas vezes como contradição entre dois pólos opostos, que talvez possam ser designados como subjetividade produtora e objetividade produzida. E a mesma dificuldade se interpõe como distância mediadora entre o sujeito que não mais reconhece a palavra subjetiva socializada e o agente que não mais reencontra a intenção subjetiva nos resultados históricos da ação. Tanto a palavra quanto a ação perturbam a intersubjetividade porque os projetos intencionais tendem a serem sempre necessariamente superados pelos outros, e isso simplesmente porque os outros também falam e também agem a partir de seus próprios projetos, outras tantas expressões da subjetividade. Não nos surpreenderemos tanto com essa analogia se compreendermos suficientemente as condições em que, para Sartre, palavra e ação estão unidas por uma íntima relação. Quais são essas condições?

"Em suma, a literatura é, por essência, a subjetividade de uma sociedade em revolução permanente. Numa tal sociedade ela superaria a antinomia entre a palavra e a ação. Decerto, em caso algum ela seria assimilável a um ato: é falso que o autor aja sobre os leitores, ele apenas faz um apelo à liberdade deles, e para que suas obras surtam qualquer efeito, é preciso que o público as assuma por meio de uma decisão incondicionada. Mas numa coletividade que se retoma sem cessar, que 
se julga e se metamorfoseia, a obra escrita pode ser condição essencial da ação, ou seja, o momento da consciência reflexiva" (SARTRE, 1989, p. 120). Dissemos há pouco que as intenções subjetivas se perdem nas condições objetivas em que são lançadas, na sociedade e na história. Entretanto, na relação dialética entre as instâncias subjetiva e objetiva, essa perda é constitutiva de realidade e de significação, isto é, torna-se, de algum modo, ganho. Num certo sentido, o escritor perde a significação subjetiva de sua obra quando o leitor a assume, conferindolhe suas próprias significações. Mas isso está dentro da relação transitiva, isto é, do "apelo à liberdade" que define a obra. Esta nada seria se o leitor não a assumisse por si mesmo, ou seja, se não se tornasse, na leitura, também um produtor de significação. É uma consciência reflexira que faz contato com a obra; um sujeito leitor é aquele que se encontra reflexivamente na obra; e esse encontro é por si mesmo significativo no sentido de produzir significações. Atender livremente, como leitor, ao apelo liv re do escritor, é a atividade de assumir a obra. $\mathrm{O}$ escritor não age sobre o leitor porque não pode subordinar à sua a liberdade do leitor. Mas este, aceitando o apelo, aceita um pacto de ação, de produção de significação; eis aí uma ação que pode se constituir como condição de outras ações. Essa relação entre liberdades constituiria uma espécie de subjetividade social, que não anularia os sujeitos singulares em questão, mas que nasceria deles, superando-os e conservando-os, numa retomada constante da coletividade por si mesma. Nesse sentido "a obra escrita pode ser condição essencial da ação”, nascida da reflexão enquanto atividade de significação.

Mas, assim como para que haja produção de significações por parte do leitor é preciso que este não aceite a obra como conjunto cristalizado de significações dadas, assim também para que a sociedade exerça essa função subjetiva de retomar-se constantemente a partir da reflexão despertada pela literatura é necessário que ela não se veja como cristalizada em suas estruturas; é preciso que os próprios significados de indivíduo, de sociedade e das relações entre eles sejam permanentemente postos em questão. Constante julgamento e metamorfose, tais são as características dessa subjetividade de uma sociedade. O escritor não age sobre o leitor; tampouco este age movido imediatamente pelo escritor; mas ambos agem 
a partir do encontro de liberdades que se expressa na produção reflexiva de significações. Seria este o "reino da liberdade humana. É claro que se trata de uma utopia. (...) Mas a utopia nos permitiu vislumbrar em que condições a idéia de literatura poderia manifestar-se na sua plenitude e na sua pureza.Tais condições, sem dúvida, não são preenchidas hoje; e é hoje que é preciso escrever" (SARTRE, 1989, p. 120).

O engajamento deve ser pensado a partir de uma experiência negativa da transitividade: não estão dadas as condições em que a coletividade, na forma de público leitor, pode responder com liberdade à liberdade do escritor; em que indivíduo e coletividade se expressariam na retomada constante de si mesmos como subjetividade social; em que não haveria dissociação entre exigências subjetivas e exigências coletivas, a literatura sendo a manifestação dessa reciprocidade ou a manifestação do universal concreto. Ao enunciar essa idéia de literatura, estamos também enunciando uma idéia de sociedade e, correspondentemente, as idéias de indivíduo e de coletividade. E ao dizer tudo isso estamos dizendo "que se trata de uma utopia", que nada disso está realizado, que nada disso talvez seja sequer realizável, mas que ainda assim "é hoje que é preciso escrever".

O engajamento deve ser pensado a partir de tudo que nos falta para realizar a idéia de literatura e a idéia de sociedade, num re gime de reciprocidade definido pela liberdade. A condição da transitividade é a reciprocidade das liberdades. Assim a literatura engajada tem como horizonte um compromisso liv re que talvez jamais venha a existir e que, no entanto, é o componente essencial da própria idéia de literatura. O critério e a motivação do engajamento é a experiência da impossibilidade de uma literatura que corresponda à sua idéia. Isso significa que no centro da própria proposta de engajamento estão enunciações cujas referências são inexistentes, não apenas no presente, mas também como possibilidade. Ora, pode o inexistente motivar uma conduta, e mesmo orientá-la de modo mais efetivo do que a realidade consolidada? Pode a experiência negativa da literatura como reciprocidade de liberddes constituir um meio de visar algum horizonte positivo para a própria literatura?

Estamos diante de uma questão ética. ${ }^{1} \mathrm{E}$ não apenas porque estaríamos falando do que a literatura deve ser - ou do que a sociedade deveser - mas por causa de uma profunda ambigüidade moral: escrever 
hoje não pode significar sujeitar-se simplesmente às condições sociais dadas para a literatura; isso seria fazer uma literatura justificadora e não criticamente comprometida. Ao mesmo tempo não há condições de se fazer uma literatura que corresponda à sua idéia, pois as condições sociais o impedem. Assim, seria preciso fazer uma literatura que pusesse em questão a si mesma e às condições históricas de sua elaboração. Ainda assim, esta literatura que seria a realização incompleta - ou mesmo negativa - de si mesma, somente se justificaria pela transitividade, isto é, pelo apelo à liberdade do leitor e pela possibilidade de que este correspondesse a tal apelo, o que, como vimos, é um requisito que não pode ser preenchido nas condições atuais. Pois o apelo a que o leitor produza significações que coloquem a ele e à sociedade em questão já é em si mesmo um chamamento à sua liberdade.

$\mathrm{Na}$ relação transitiva em que o leitor é chamado a participar como produtor de significações, cabe ao escritor, o elo originante deste vínculo, arcar com a responsabilidade inerente à criação da obra a partir da qual há de se produzir o apelo. Uma vez que o homem é originariamente liberdade, e posto que liberdade é escolha originária, isto é, invenção simultânea do ato, do critério, do valor e da finalidade, esse começo radical que em cada ato define o sujeito como projeto de si mesmo (Para-si), é sempre responsabilidade em sentido total e absoluto. Que a liberdade absoluta seja vivida na contingência é apenas um sinal de que a contingência, sendo também absoluta, deixa o homem entregue a si mesmo. É exatamente a ausência de uma essência pré-determinante que confere à existência esse estranho e paradoxal caráter absoluto. "O homem, que se explica simultaneamente por tantas e tantas causas, no entanto carrega sozinho o peso de si mesmo. Nesse sentido, a liberdade pode passar por uma maldição, ela é uma maldição. Mas é também a única fonte da grandeza humana" (SARTRE, 1987a, p. 27). A fatalidade da liberdade está em que ela é um poder que o homem possui e ao qual ao mesmo tempo está irremediavelmente submetido na medida em que não pode se furtar a exercê-lo. Aí estaria, talvez, o princípio do engajamento, como que já inscrito na própria estrutura ontológica da subjetividade enquanto processo existencial marcado pela contingência.

A contingência universal manifesta-se concretamente na facticidade que define cada situação histórica através dos limites que a época impõe 
ao exercício da liberdade. Como compatibilizar os limites das ações livres com o caráter absoluto da liberdade? Seria cômodo fugir ao paradoxo entendendo que o alcance da liberdade seria sempre relativo às limitações históricas da época em que se vive. Mas o relativismo é um álibi, na medida em que me permite dividir a responsabilidade pelos atos e pelas conseqüências das minhas decisões subjetivas com as condições objetivas nas quais me é dado viver. Ora, o caráter originário e radical da liberdade impede de aceitar o meio-termo relativista. Assim, por paradoxal que seja, é preciso compreender a liberdade experimentada como absoluto dentro dos limites da situação histórica. "Bem longe de sermos relativistas, afirmamos bem alto que o homem é um absoluto. Mas ele o é na sua hora, no seu meio, na sua terra. O que é absoluto, o que mil anos de história não podem destruir, é essa decisão única, incomparável, insubstituível, que ele toma em tal ou qual momento, a propósito de tais ou quais circunstâncias" (SARTRE, 1987a, p. 15). Dito de outro modo, a liberdade não é relativa porque cada ato, cada decisão, cada escolha, ocorrem num regime de singularidade, isto é, na superação e na conservação da particularidade das condições subjetivas e da generalidade das condições objetivas. O sujeito não é livre em si mesmo, porque nenhum sujeito existe $\mathrm{em}$ si como coisa ou como entidade metafísica, já que a subjetividade nada mais é do que o movimento de autoconstituição de si mesma, num processo totalizante de identificação destinado a nunca se completar.

Já que nunca se é livre para deixar de ser livre, não se pode praticar a evasão. $\mathrm{O}$ escritor não pode evadir-se da sua hora, de seu meio, de seu tempo, pois quando tenta fazê-lo, o faz ainda a partir de uma liberdade situada que escolhe mascarar. A fatalidade da liberdade supõe então o grande arco que une escolha e responsabilidade, mesmo quando os resultados objetivos das ações não correspondam às intenções subjetivas. Nesse sentido o engajamento em Sartre tem algo da aposta pascaliana: é preciso apostar, vous êtes embarqués. Mas como fatalidade e liberdade se identificam, como o destino é sempre a construção prática de uma vida e de uma história, a responsabilidade é assumida como corolário de uma liberdade da qual não se pode fugir. Esta é a razão pela qual é necessário que o escritor "abrace estreitamente sua época; ela é sua única chance; ela é feita para ele e ele é feito para ela" (SARTRE, 1987a, p. 13). Este é o significado concreto da situação, como hora e como lugar da liberdade, 
mas ao mesmo tempo como escolha absoluta, isto é, como invenção de si e de seu tempo.

Por que invenção? Porque liberdade é antes de tudo a experiência da possibilidade enquanto compromisso com o futuro. A noção de projeto existencial - e de projeto histórico - faz com que "uma época, como um homem, seja antes de tudo um futuro". Entenda-se: a escolha é radical porque nela não está implicada necessariamente a realização; uma escolha é sempre um começo de ação que pode ou não se realizar ou que pode realizar-se de modo inteiramente diverso de seu propósito inicial, pois a decisão compromete o futuro enquanto projeto. É por isso que o teor ético - ético-político - do engajamento exclui completamente qualquer cálculo moral. É como se a possibilidade fosse uma experiência em si mesma e o compromisso com o futuro fosse uma aposta no inexistente, ou naquilo que não existe ainda. Nesse sentido a contingência, se de um lado limita a certeza pela ausência de necessidade, de outro abre o campo do possível, que significa a ação liv re motivada não pela realidade - pelo presente - mas pelo inexistente - pelo futuro que ainda não é real. E como essa experiência do que não é, sendo apenas possível, é escolha radical, é também invenção de finalidade e de valor de modo imanente à ação. Assim, é pela imanência do sujeito a si mesmo, isto é, à sua liberdade, que ele pode transcender-se a si mesmo e à sua época, negar a condição presente em nome de uma condição futura. Contingência e negação permitem o exercício da liberdade pela qual o "homem inventa o homem".

Percebemos assim a relação entre a definição da literatura engajada como liberdade que apela à liberdade e a compreensão da literatura como negatividade, algo que está ligado ao entendimento da arte como liberdade de negar o existente por via da intencionalidade imaginante da consciência. Mas é preciso explicitar essa negatividade ou esse poder negador, pois ele pode ser entendido como uma irresponsabilidade inerente ao artista. Isso ocorreu no caso da negatividade romântica pela qual o gênio se isola do mundo; por uma literatura governada pelo princípio da arte pela arte, como em Flaubert; pela negatividade da palavra que recusa a transitividade significativa e se encerra na sua pura materialidade, como em certas tendências modernas da poesia; ou pela contestação surrealista da ordem da significação. Para Sartre, em nenhum desses casos 
a negatividade aparece como instrumento de engajamento, pois em nenhum deles há um compromisso verdadeiro com a negação. São exercícios solipsistas nos quais a literatura trai a sua função transitiva. Ou são meios de que o artista se serve para separar a liberdade da responsabilidade. A negatividade autêntica se expressa no procedimento literário pelo qual é oferecido ao leitor um "espelho crítico" diante do qual ele é levado a negar a si mesmo e ao contexto de sua experiência histórica. Isso só é possível na prosa, razão pela qual, pelo menos na contemporaneidade, o romance é o gênero de arte em que o engajamento se torna possível.

Há que se levar em conta, entretanto, que o escritor é um intelectual, mas que nem todo intelectual é um escritor de romances, razão pela qual é preciso dizer algo acerca dessa questão mais geral que é o engajamento do intelectual, entendendo o processo histórico de seu aparecimento e de sua transformação. Através dessa análise Sartre chega a distinções históricas importantes: o intelectual na Idade Média, isto é, o clérigo, situa-se dentro de um determinado regime de interlocução definido pelo círculo fechado daqueles que têm acesso às letras, e que na sua quase totalidade estão ligados à Igreja. O intelectual dos séculos XVI e XVII também escreve para outros intelectuais, mas sua referência sócio-política é a nobreza, que exerce um mecenato direto e indireto, e o desejo do mecenas é ver-se retratado na obra que patrocina. O intelectual do século XVIII é aquele que já se relaciona com um público no sentido moderno do termo, e tem uma relação orgânica com a burguesia enquanto classe ascendente, como é o caso dos philosophes. No século XIX a burguesia, agora classe dominante, já não necessita mais de laços orgânicos com o intelectual que a represente, e surge então uma espécie sutil e complicada de recusa mútua, que não exclui a dependência do intelectual do público burguês, como se vê em Flaubert. Há uma dissolução do público a partir da condição ambígua do intelectual, que recusa sua classe de origem sem que, entretanto, venha a desvincular-se dela.

Essa separação problemática tem sua razão no fato de que a burguesia consolidada já não precisa tanto de intelectuais que a justifiquem, mas muito mais de técnicos que atuem como funcionários do progresso naquilo que realmente interessa: a promoção do saber prático. $\mathrm{O}$ intelectual contemporâneo surge quando esse "técnico do saber prático" toma consciência, em si mesmo e através de seu trabalho, do caráter formal da 
universalidade proclamada pela burguesia nos grandes princípios das revoluções modernas. Ao perceber que os princípios universais são abstratos e mascaram interesses concretos de classe, o "técnico do saber prático" objetiva sua crise de consciência em crítica do sistema, tornandose assim um intelectual, isto é, assumindo um compromisso de negação do presente que é ao mesmo tempo de construção do futuro. O técnico torna-se um intelectual quando coloca seus instrumentos de conhecimento da realidade a serviço de uma decifração crítica dessa mesma realidade. Mais concretamente, quando recusa o humanismo universalista e abstrato como o pano de fundo de uma sociedade pautada por interesses particularistas impostos pela classe dominante.

Assim, como todo sujeito, o intelectual é aquele que conhece o mundo, a si mesmo e se dá a conhecer aos demais objetivando as significações vividas no plano de uma consciência separada de si mesma e que expressa singularmente as condições gerais de uma sociedade dividida. Essa objetivação da subjetividade nesse caso se faz, porém, por meio de instrumentos racionais de que o intelectual dispõe, e que lhe foram primeiramente fornecidos pela burguesia em vista de sua própria justificação. A origem da consciência crítica é, pois, a contradição vivida subjetivamente e objetivada no compromisso de representá-la intelectualmente. É preciso acrescentar que essa representação e o engajamento que ela supõe também são permeados pela contradição.

As contradições situam-se primeiramente, como é óbvio, na experiência humana concreta que se desenvolve como história individual e coletiva; mas situam-se também no plano da expressão, isto é, na passagem do processo vivido de subjetivação ao plano objetivo em que esse processo deve expressar-se através da linguagem. Essa passagem é complexa porque não se trata simplesmente do trânsito linear da subjetividade à objetividade: a própria subjetividade se forma pela incorporação individual das condições objetivas que depois são exteriorizadas por sujeitos singulares, isto é, por indivíduos que são particulares na medida em que carregam em si a unive rsalidade de que participam, nos vários aspectos da existência. Esse paradoxo da existência, que consiste em estar em si estando fora de si, manifesta-se na atividade expressiva pelo jogo de presença e ausência das significações. "Se o escritor adota a linguagem corrente, não é apenas na medida em que a linguagem pode transmitir 
um saber, mas também na medida em que não o transmite" (SARTRE, 1994, p. 57). Aqui não se trata apenas da velha idéia de que haveria no fazer artístico uma luta pela expressão derivada da diferença entre o que deve ser expresso e os meios expressivos de que se dispõe, dificuldade que levaria o artista a inventar e a criar. Para Sartre, essa diferença, que na verdade é uma contradição, deve ser vista como constitutiva da expressão.

Para que haja transitividade no sentido do apelo de uma liberdade à outra na produção de significações, a linguagem utilizada pelo escritor não pode ser, evidentemente, uma estrutura léxica e gramatical consolidada, como no limite acontece com as linguagens técnicas em que a eficiência instrumental depende da univocidade dos significados. O escritor, diz Sart re, utiliza a língua comum que se desenvolve liv remente, aquela em que os acordos tácitos são demasiado frágeis para garantir uma estabilidade significativa. Ao mesmo tempo, há um campo de possibilidades instrumentais que são dados em cada época, e que possui limites definidos dentro dos quais o escritor deve se mover. Ele o fará contraditoriamente: ao mesmo tempo em que os limites restringem as possibilidades expressivas, estas se realizarão pela transgressão desses mesmos limites. As duas coisas ocorrem ao mesmo tempo porque o escritor simultaneamente se submete às limitações e as transcende, como acontece com todo exe rćcicio de liberdade em situação. Haverá assim uma deformação no próprio ato de constituição da expressão. E a subjetividade que se objetiva ao expressar-se também sofrerá deformação. Isso significa que, na dimensão objetiva, o resultado da expressão pode ser mais ou menos do que a intenção subjetiva, assim como pode ser outra coisa ou também outra coisa. ${ }^{2}$

Se de um lado essa deformação frustra a intenção significativa (Sartre diz que a época nos rouba o pensamento), de outro ela manifesta a liberdade e a transitividade constitutivas da literatura, ou o seu regime próprio de relação intersubjetiva. $O$ engajamento literário exige a transitividade porque a literatura tem uma função, que é falar ao outro, e de modo a que este produza atos de significação que o levem a conhecer-se e ao seu contexto. Essa função é social, mas isso não rebaixa a literatura - ou não deveria rebaixá-la - a simples instrumento ideológico. Como vimos, essa função social é cumprida por via da liberdade, do apelo da liberdade do escritor à liberdade do leitor. Mas, também como vimos, essa função é 
cumprida conscientemente na medida em que a prosa literária fale o mais diretamente possível acerca do tempo e do espaço historicamente compartilhados. É nesse sentido que Sartre entende que pode emitir um julgamento (negativo) acerca do espírito de análise de Proust e da omissão de Flaubert e Baudelaire em relação aos acontecimentos da época em que viveram. A época de cada um é também a sua oportunidade de vida, e a sua "única chance". Ela lhe concerne, pois, intimamente. Até porque, na medida em que o escritor não pode se evadir, ele exprimirá sua época e sua situação nas próprias tentativas de evasão, como Sartre mostra nos estudos sobre Baudelaire e Flaubert.

Enfim, a função social da literatura deriva de que ela é sempre uma produção histórica, e de que os escritores não detêm o privilégio de uma subjetividade supra-histórica, sendo também eles histórias individuais, processos existenciais de subjetivação inscritos na contingência. $O$ engajamento é, na sua acepção mais geral, se assim podemos dizer, conseqüência de que o homem é uma questão para si mesmo, e uma questão, ao mesmo tempo, pessoal, social, metafisica e histórica, que se constrói no entremeio de uma relação em que a subjetividade somente se revela ao objetivar-se, revelação que supõe, portanto, um processo em que a subjetividade não se dissolva nas determinações objetivas. Um conhecimento que saiba manter essa tensão dialética é aquele que Sartre designa como o do homem total, que não é uma representação totalizada do homem, mas das múltiplas significações que o totalizariam. "Totalmente engajado e totalmente livre", por mais dificil que seja essa elaboração de uma representação totalizante feita de oposições e contradições, que devemos considerar sinteticamente, embora sem a pretensão de chegar a uma síntese acabada. E por isso mesmo a literatura não pode ser doutrina, não pode ser exposição de totalidades, sobrevôo universal, tese definitiva sobre a "natureza" humana, nem pode ter qualquer critério diretor que não seja a responsabilidade do escritor. Este é, na verdade, responsável pelo engajamento e pela literatura, e cada um deve resolver, como puder, os eventuais conflitos que venham a nascer dessa indissociabilidade. "Lembro, com efeito, que na "literatura engajada', o engajamento não pode, em nenhum caso, fazer esquecer a literatura e que nossa preocupação deve ser a de servir a literatura infundindo-lhe sangue novo, assim como servir a coletividade tentando lhe oferecer a literatura que lhe convém" (SARTRE, 1987a, p 30). 
1 Tal questão é assim formulada por Jeannette Colombel: "Peut-on dissocier une éthique de l'engagement d'espoirs historiques qui ont fait faillite? Peut-on résister au mal sans visée du bien, fût-il à créer? Peut-on intervenir dans l'incertitude?" (COLOMBEL, 1985, p. 434).

2 Cf. os exemplos de Sade e do Jansenismo (SARTRE, 1987b, p. 161 ss).

\section{Referências bibliográficas}

COLOMBEL, J. 1985. Sartre: un homme en situations. Paris: Gallimard.

SARTRE, J.-P. 1987a. Présentation de "Les Temps Modernes ». Situations II. Paris: Gallimard.

Fragment inédit de Qu'est-ce que la littérature? CONTAT, M. e RYBALKA, M. 1970. Les écrits de Sartre. Paris: Gallimard. 1987b. Questão de Método. Tradução Bento Prado Jr. São Paulo: Nova Cultural. 1989. Que é literatura? Tradução Carlos F. Moisés. São

Paulo: Ática. 1994. Em defesa dos intelectuais. São Paulo: Ática. 
○

O 